\title{
Measuring Flesh Color Variability among Processing Clingstone Peach Genotypes Differing in Carotenoid Composition
}

\author{
Kenneth R. Tourjee \\ Agroforestry Center, University of Missouri, Columbia, MO 65211 \\ Diane M. Barrett and Marisa V. Romero \\ Food Science and Technology Department, University of California, Davis, CA 95616 \\ Thomas M. Gradziel \\ Department of Pomology, University of California, Davis, CA 95616
}

\begin{abstract}
Additional INdex words. Prunus, CIELAB, principal component analysis, path analysis, $\beta$-carotene, $\beta$-cryptoxanthin
Abstract. The variability in fresh and processed fruit flesh color of six clingstone processing peach [Prunus persica (L.) Batsch] genotypes was measured using CIELAB color variables. The genotypes were selected based on the relative fruit concentrations of $\beta$-carotene and $\beta$-cryptoxanthin. Significant $(p<0.0001)$ differences were found among the genotypes for the $L^{*}, a^{*}$, and $b^{*}$ color variables of fresh and processed fruit. Mean color change during processing, as measured by $\triangle \mathrm{E}_{\mathrm{LAB}}$, was greatest for 'Ross' and least for 'Hesse'. A plot of the first two principal components (PCs) obtained from PC analysis of the $L^{*}, a^{*}$, and $b^{*}$ variables for fresh and processed fruit revealed three clusters of genotypes that match groupings based on the relative concentrations in fresh fruit of carotenoid pigments. Path analysis showed that variation in $\beta$-cryptoxanthin concentration was more precisely determined from color data than $\beta$-carotene concentration. Chemical names used: $\beta$ - $\beta$-carotene ( $\beta$-carotene), (3R)- $\beta$ - $\beta$-caroten-3-ol ( $\beta$-cryptoxanthin).
\end{abstract}

Worldwide processing clingstone peach production was $>1.2$ million $\mathrm{Mg}$ in 1995. California produced $392,000 \mathrm{Mg}$, representing about one-third of the global production and $40 \%$ of the total U.S. fresh and processed peach production (Edward E. Judge and Sons, Inc. 1996; USDA National Agricultural Statistics Service, 1996). The cash value of the used California crop, bulk fruit at first delivery point, exceeded $\$ 90$ million. Fruit quality is a major determinant of cash value and color is a primary component of quality (Francis, 1995). Consequently, peach flesh color has been identified as an important trait in clingstone peaches (Fuleki and Cook, 1976; Gradziel and Wang, 1993; Kader et al., 1982; Leonard et al., 1961). However, the range of CIELAB color variability of processing clingstone peach is not yet characterized. Understanding the extent of peach color variability is an important step toward improving crop quality.

Carotenoids are the major pigments of peaches. $\beta$-Carotene and $\beta$-cryptoxanthin have been reported to be the primary provitamin A carotenoids (Curl, 1959; Khachik et al., 1989; MacKinney, 1937; Mitchell, 1948); $\beta$-carotene has twice the provitamin A activity as $\beta$-cryptoxanthin. Anthocyanins play a role in the flesh color of fresh-market peaches but are heat labile, and selection against their presence has bred them out of processing clingstone peaches (Kader et al,, 1982). While carotenoid stability with respect to thermal processing may be a factor in the discoloration of processed fruit, its role is poorly understood but probably related to genotype-specific carotenoid composition

Received for publication 1 Apr. 1997. Accepted for publication 19 Nov. 1997. Research partly supported by funds from the Calif. Cling Peach Advisory Board. We express our gratitude for the insightful comments of Adel A. Kader, Douglas V. Shaw, and William A. Williams. James A. Harding generously provided computer facilities for the data analysis. Use of trade names does not imply endorsement of the products named nor criticism of similar ones not named. The cost of publishing this paper was defrayed in part by the payment of page charges. Under postal regulations, this paper therefore must be hereby marked advertisement solely to indicate this fact. and type of thermal process used. Although the relative contribution of $\beta$-carotene and $\beta$-cryptoxanthin to processed flesh color has not been determined, Kader et al. (1982) have shown that a relationship exists between tristimulus colorimetry and total carotenoid content and other quality attributes. Lauber et al. (1967) found tristimulus colorimetry to be an efficient means on which to base selection for high carotenoid genotypes in sweetpotato [Ipomoea batatas (L.) Lam.].

CIELAB color notation based on spectrophotometric colorimetry is a convenient way to define color precisely and objectively (Voss, 1992). This system locates color in a space defined by lightness $\left(\mathrm{L}^{*}\right)$, range from red to green $\left(\mathrm{a}^{*}\right)$, and range from yellow to blue $\left(\mathrm{b}^{*}\right)$. It has been successfully applied to the study of many pomological crops, including strawberries (Fragaria $\times$ ananassa Duch.) (Shaw, 1991), apples (Malus $\times$ domestica Borkh.) (Singha et al., 1991), and raspberries (Rubus idaeus L.) (Robbins and Moore, 1990). Delwiche et al. (1985) studied peach skin color using CIELAB notation and concluded that $a^{*}$ is a useful fruit maturity index. Flesh or mesocarp a* score has been reported to be a useful index for fruit maturity and processed fruit quality in clingstone peach (Fuleki and Cook, 1976; Kader et al., 1982; Leonard et al., 1961). Robertson et al. (1991) concluded that ground color $\mathrm{a}^{*}$ scores are too variable to be useful as a universal maturity index in freestone peach and recommended the use of hue angle (arctangent $b^{*} / a^{*}$ ).

This study's objective was to describe the variability of the $\beta$ carotene and $\beta$-cryptoxanthin carotenoids in relation to CIELAB variables $L^{*}, a^{*}$, and $b^{*}$ for peach flesh color among diverse clingstone peach genotypes. The magnitude of color change that occurs with processing was also investigated. Descriptive statistics concerning these variables could demarcate the color space currently available to the peach processing industry and provide a starting point for discussions towards optimizing peach carotenoid composition as it affects processing stability of color and nutritive value. 
Table 1. ANOVA (type III sums of squares) for the $\mathrm{L}^{*}, \mathrm{a}^{*}$, and $\mathrm{b}^{*}$ scores of fresh and processed fruit with genotypes as a fixed effect; the subscript $f$ denotes fresh and $p$ denotes processed.

\begin{tabular}{|c|c|c|c|c|}
\hline $\begin{array}{l}\text { Dependant } \\
\text { variable }\end{array}$ & $\begin{array}{l}\text { Source of } \\
\text { variation }\end{array}$ & df & $\mathrm{ms}^{\mathrm{z}}$ & $\mathrm{F}^{\mathrm{y}}$ \\
\hline \multirow[t]{3}{*}{$\overline{\mathbf{L}_{\mathrm{f}}^{*}}$} & Genotype & 5 & 519.15 & 166.64 \\
\hline & Error & 194 & 3.11 & \\
\hline & Total & 199 & & \\
\hline \multirow[t]{3}{*}{$a_{f}^{*}$} & Genotype & 5 & 651.42 & 156.37 \\
\hline & Error & 194 & 4.17 & \\
\hline & Total & 199 & & \\
\hline \multirow[t]{3}{*}{$b_{f}^{*}$} & Genotype & 5 & 159.58 & 26.43 \\
\hline & Error & 194 & 6.04 & \\
\hline & Total & 199 & & \\
\hline \multirow{3}{*}{$\mathrm{L}_{\mathrm{p}}{ }^{*}$} & Genotype & 5 & 83.59 & 14.46 \\
\hline & Error & 194 & 5.61 & \\
\hline & Total & 199 & & \\
\hline \multirow{3}{*}{$a_{p}^{*}$} & Genotype & 5 & 431.04 & 126.97 \\
\hline & Error & 194 & 3.39 & \\
\hline & Total & 199 & & \\
\hline \multirow{3}{*}{$b_{p}^{*}$} & Genotype & 5 & 416.41 & 47.03 \\
\hline & Error & 194 & 8.85 & \\
\hline & Total & 199 & & \\
\hline \multirow{3}{*}{$\mathbf{E}_{\mathrm{LAB}}$} & Genotype & 5 & 685.56 & 78.37 \\
\hline & Error & 194 & 8.75 & \\
\hline & Total & 199 & & \\
\hline
\end{tabular}

${ }^{\mathrm{z} m s}=\mathrm{ss} / \mathrm{df}$.

${ }^{\mathrm{y}} \mathrm{F}$ statistic $=\mathrm{ms}$ genotype $/ \mathrm{ms}$ error. All dependant variables were significant at $P<0.0001$.

\section{Materials and Methods}

Clingstone peach genotypes representing the range of flesh colors used by the processing peach industry were evaluated. Six genotypes were selected for testing based on diversity in perceived flesh color and preliminary pigment analysis. 'Halford' and 'Corona' represent old California industry standards for yellow cling peach color quality. 'Ross' has a golden-yellow flesh color and is emerging as the new color standard. 'Hesse' and 'UC18,8-23', derived from 'Australian Muir' and 'Transvaal Cling', display increasing levels of orange color. 'Kakamas' is a South African genotype with a dull orange flesh color. Peaches were harvested at stage III according to Leonard et al. (1961), being fully ripe with no trace of green in the fruit epidermis. Peaches were stored for 3 to $4 \mathrm{~d}$ at 2 to $5^{\circ} \mathrm{C}$ to remove field heat and hold fruit before fresh color determination and processing. During processing, the fruit were pitted, halved (Filper Torque Pitter), lye peeled, and canned in no. $21 / 2$ cans. Each can contained $540 \mathrm{~g}$ fruit and $820 \mathrm{~g}$ of $30^{\circ}$ Brix syrup. Cans were cooked at $105^{\circ} \mathrm{C}$ for $12 \mathrm{~min}$ in a rotary cooker (FMC Steritort), air cooled for $15 \mathrm{~min}$ to $\approx 26^{\circ} \mathrm{C}$, then stored for 8 months at 18 to $20^{\circ} \mathrm{C}$ before color of the processed fruit was measured.
Color of fresh fruit flesh at a depth of $1 \mathrm{~cm}$ at the equatorial zone of one of the fruit cheeks was measured with a colorimeter (Agtron Colortmet, Reno, Nev.) having a 30-mm-diameter viewing area, and directional $45^{\circ}$ illumination, calibrated to a white tile. CIELAB $L^{*}, a^{*}$, and $b^{*}$ variables and $D_{65} / 10^{\circ}$ settings (Hunt, 1987) were used for all measurements. Flesh color has been shown to be the most useful fruit quality and maturity index for processing peach and is the maturity index used in industry grading (Gradziel, 1994; Kader et al., 1982). The number of fruit measured per genotype is listed in Table 2. Each fruit was marked for identification and after processing and storage the fruit color remeasured. Processed fruit color was measured in an identical manner and at the surface site of the original color measurement. Subscripts of color variables $\left(L_{\mathrm{f}}{ }^{*}, a_{\mathrm{f}}{ }^{*}\right.$, and $b_{\mathrm{f}}{ }^{*}$, and $\mathrm{L}_{\mathrm{p}}{ }^{*}, \mathrm{a}_{\mathrm{p}}{ }^{*}$, and $\left.\mathrm{b}_{\mathrm{p}}{ }^{*}\right)$ refer to measurements made on fresh (f) and processed (p) fruit, respectively, and are used where necessary to simplify discussion. Color change $\left(\Delta \mathrm{E}_{\mathrm{LAB}}\right)$ was calculated from the color-difference formula (Hunt, 1987) and is the Euclidean distance in CIELAB color space between the paired before and after processing measurements of flesh color. It is a measure of the magnitude of difference between two colors. $\Delta \mathrm{L}$, $\Delta a$, and $\Delta b$ are the differences between fresh and processed fruit of $L^{*}, a^{*}$, and $b^{*}$, respectively.

Table 2. Mean and (standard error) estimates for CIELAB color variables of fresh and processed peaches by genotype.

\begin{tabular}{|c|c|c|c|c|c|c|c|}
\hline \multirow[b]{2}{*}{ Genotype } & \multirow[b]{2}{*}{$\mathbf{n}$} & \multicolumn{3}{|c|}{ Fresh } & \multicolumn{3}{|c|}{ Processed } \\
\hline & & $\mathrm{L}^{*}$ & $a^{*}$ & $b^{*}$ & $\mathrm{~L}^{*}$ & $a^{*}$ & $b^{*}$ \\
\hline$\overline{\mathrm{UC}} 18,8-23$ & 37 & $61.1(0.2) \mathrm{cd}^{\prime}$ & $22.2(0.2) b$ & $49.3(0.3) \mathrm{cd}$ & $51.4(0.2) \mathrm{cd}$ & $15.9(0.2) \mathrm{a}$ & $51.9(0.4) \mathrm{c}$ \\
\hline Corona & 36 & $62.8(0.3) b c$ & $15.2(0.4) \mathrm{d}$ & $54.6(0.4) \mathrm{a}$ & $53.7(0.4) a b$ & $11.1(0.4) \mathrm{c}$ & $52.2(0.7) \mathrm{c}$ \\
\hline Halford & 37 & $62.7(0.2) b$ & $16.8(0.4) \mathrm{c}$ & $54.2(0.4) \mathrm{a}$ & $53.4(0.5) \mathrm{ab}$ & $11.5(0.4) b c$ & $53.0(0.5) b c$ \\
\hline Hesse & 18 & $61.5(0.3) b c$ & $16.2(0.4) \mathrm{cd}$ & $49.8(0.7) \mathrm{cb}$ & $54.4(0.2) \mathrm{a}$ & $11.6(0.4) b$ & $54.9(0.5) a b$ \\
\hline Kakamas & 39 & $60.1(0.2) \mathrm{d}$ & $23.8(0.4) \mathrm{a}$ & $51.4(0.2) \mathrm{b}$ & $52.0(0.2) b c$ & $17.2(0.3) \mathrm{a}$ & $56.5(0.4) \mathrm{a}$ \\
\hline Ross & 33 & $70.9(0.5) \mathrm{a}$ & $12.7(0.5) \mathrm{e}$ & $51.6(0.5) \mathrm{cd}$ & $49.9(0.5) \mathrm{d}$ & $7.7(0.3) \mathrm{d}$ & $46.2(0.6) d$ \\
\hline
\end{tabular}

${ }^{\bar{x}}$ Means followed by the same letter are not significantly different by Hochberg's GT2 method at $\alpha=0.05$ and $\mathrm{df}=205$. 
Table 3. Mean color difference and (standard error) of genotypes between fresh and processed fruit.

\begin{tabular}{lcccc}
\hline \hline & & \multicolumn{3}{c}{ Proportion of $\Delta \mathrm{E}_{\mathrm{LAB}}$} \\
\cline { 3 - 5 } Genotype & $\Delta \mathrm{E}_{\mathrm{LAB}}$ & $\Delta \mathrm{L}$ & $\Delta \mathrm{a}$ & $\Delta \mathrm{b}$ \\
\hline $\mathrm{UC} 18,8-23$ & $12.2(0.3) \mathrm{b}^{z}$ & $0.62(0.02)$ & $0.28(0.02)$ & $0.10(0.02)$ \\
Corona & $11.3(0.6) \mathrm{bc}$ & $0.64(0.04)$ & $0.18(0.03)$ & $0.18(0.03)$ \\
Halford & $12.1(0.5) \mathrm{bc}$ & $0.64(0.04)$ & $0.24(0.03)$ & $0.12(0.02)$ \\
Hesse & $9.9(0.3) \mathrm{c}$ & $0.54(0.05)$ & $0.15(0.02)$ & $0.31(0.06)$ \\
Kakamas & $12.2(0.3) \mathrm{b}$ & $0.46(0.03)$ & $0.31(0.02)$ & $0.23(0.03)$ \\
Ross & $22.8(0.8) \mathrm{a}$ & $0.86(0.02)$ & $0.07(0.01)$ & $0.07(0.001)$ \\
\hline
\end{tabular}

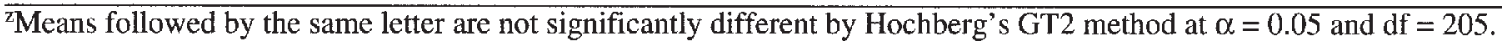

Table 4. ANOVA (type III sums of squares) for concentration of $\beta$-carotene and $\beta$-cryptoxanthin ( $\mu \mathrm{g}^{-\mathrm{kg}^{-1}}$ fresh mass).

\begin{tabular}{llrrr}
\hline \hline $\begin{array}{l}\text { Dependant } \\
\text { variable }\end{array}$ & $\begin{array}{l}\text { Source of } \\
\text { variation }\end{array}$ & df & $\mathrm{ms}^{2}$ & $\mathrm{~F}^{\mathrm{y}}$ \\
\hline$\beta$-Carotene & Genotype & 5 & $7,277,424$ & 43.38 \\
& Error & 24 & 167,744 & \\
$\beta$-Cryptoxanthin & Total & 29 & $1,886,742$ & 34.33 \\
& Genotype & 5 & 54,966 & \\
& Error & 24 & & \\
& Total & 29 & & \\
\hline
\end{tabular}

${ }^{\mathrm{z}} \mathrm{ms}=\mathrm{ss} / \mathrm{df}$

${ }_{\mathrm{F}}^{\mathrm{F}}$ statistic $=\mathrm{ms}$ genotype $/ \mathrm{ms}$ error. All significant at $P<0.0001$.

$\beta$-Carotene and $\beta$-cryptoxanthin were determined from extracted raw fruit samples that were saponified to remove interfering lipids and chlorophyll; five fruit of each genotype were separately prepared and analyzed. Saponification was carried out with $3.0 \% \mathrm{KOH}$ at $60{ }^{\circ} \mathrm{C}$ for $1 \mathrm{~h}$. The saponified extracts were analyzed by high-performance liquid chromatography using a chromatograph (Hewlett-Packard 1090A) equipped with a diode array detector and $\mathrm{C} 18$ column $(225 \times 0.45 \mathrm{~mm}, 5 \mu \mathrm{m}$ Microsorb, Rainin Instrument Co. Woburn, Mass.) at $25^{\circ} \mathrm{C}$. Samples were eluted isocratically. Mobile phase consisted of $60 \%$ acetonitrile and $40 \%$ isopropanol mobile phase at $1 \mathrm{~mL} \cdot \mathrm{min}^{-1}$. Carotenoids were detected at $450 \mathrm{~nm}$. Results were recorded as peak areas at 9.9 and $19.9 \mathrm{~min}$, as verified by standard $\beta$-cryptoxanthin and $\beta$ carotene solutions respectively. Saponification and analysis were carried out in darkness to protect from light degradation.

Statistical analysis was done using the General Linear Model and PRINCOMP procedures of the Statistical Analysis System (SAS Institute, Cary, N.C.). Genotypes were treated as fixed effects for the analysis of variance procedure. Mean separation tests of color variables for each genotype were done by Hochberg's GT2 method because of unequal sample sizes (Hochberg, 1974). Principal component (PC) analysis was done using the correlation matrix for individual fruit. Path analysis was done as described in Williams et al. (1990).

\section{Results and Discussion}

Significant differences among genotypes were found for all color variables (Table 1). The mean estimates of each variable are provided in Table 2 for individual genotypes. The mean estimates of $\mathrm{L}^{*}$ and $\mathrm{a}^{*}$ for each genotype decreased with processing (Table 2 ). The mean estimate for $b^{*}$ did not change consistently across genotypes with processing. 'Ross' is unique (by Hochberg's GT2 means separation) among the genotypes studied in terms of $\mathrm{L}_{\mathrm{f}}^{*}$, $\mathrm{a}_{\mathrm{f}}{ }^{*}, \mathrm{a}_{\mathrm{p}}{ }^{*}, \mathrm{~b}_{\mathrm{p}}{ }^{*}$, and $\Delta \mathrm{E}_{\mathrm{LAB}}$.

The mean $\Delta \mathrm{E}_{\mathrm{LAB}}$ estimates of genotypes ranged from 9.9 to 22.8 (Table 3). This variable measures the color change that occurs with processing. The magnitude of $\Delta \mathrm{E}_{\mathrm{LAB}}$ is important because of the low precision with which the color of processed fruit can be predicted from fresh fruit. The relative importance to $\Delta \mathrm{E}_{\mathrm{LAB}}$ of each of its components varied among the genotypes, but $\Delta \mathrm{L}$ was the dominant component for each genotype (Table 3). 'Ross' was the genotype with the largest $\Delta \mathrm{E}_{\mathrm{LAB}}$ and greatest proportion due to $\Delta \mathrm{L}$. 'Hesse' had the smallest $\Delta \mathrm{E}_{\mathrm{LAB}}$ estimate and was the genotype with the largest $\Delta b$ contribution. The $\Delta \mathrm{E}_{\mathrm{LAB}}$ estimate for 'Kakamas' had the most balanced contribution among its components. This variation in the relative contribution of the $\Delta \mathrm{E}_{\mathrm{LAB}}$ components implies genotype differences in pigment composition or flesh browning potential among processing peaches. The dominant role of $\Delta \mathrm{L}$ suggests that flesh darkening is a more important factor in the color change of processed peaches than previously recognized (Lee, et al., 1990). A slight increase in $\mathrm{L}_{\mathrm{f}}$ is normal during peach fruit ripening and consequently this increase could be attributable to enzymatic or nonenzymatic browning or other biochemical and ultrastructural processes operating during ripening.

Genotype differences also exist for flesh carotenoid concentration (Table 4). The carotenoid concentration of the genotypes are categorized as either high or low (Table 5): 'Halford' and 'Corona' had high $\beta$-carotene and low $\beta$-cryptoxanthin, 'Kakamas' and 'UC18,8-23' had low $\beta$-carotene and high $\beta$-cryptoxanthin, and 'Ross' and 'Hesse' had low $\beta$-carotene and low $\beta$-cryptoxanthin.

Table 5. Mean etimates and (standard error) of carotenoid concentration $\left(\mu \mathrm{g} \cdot \mathrm{kg}^{-1}\right.$ fresh mass).

\begin{tabular}{lcc}
\hline \hline Genotype & $\beta$-carotene & $\beta$-cryptoxanthin \\
\hline UC18,8-23 & $362(3.9) \mathrm{c}^{\mathrm{z}}$ & $2743(107.8) \mathrm{a}$ \\
Corona & $1308(111.4) \mathrm{b}$ & $579(75.3) \mathrm{b}$ \\
Halford & $1869(208.3) \mathrm{a}$ & $1035(149.8) \mathrm{b}$ \\
Hesse & $585(93.2) \mathrm{c}$ & $1230(152.1) \mathrm{b}$ \\
Kakamas & $682(28.8) \mathrm{c}$ & $3391(364.5) \mathrm{a}$ \\
Ross & $300(25.1) \mathrm{c}$ & $474(74.7) \mathrm{b}$
\end{tabular}

${ }^{\mathrm{z}}$ Means followed by the same letter are not significantly different by Duncan's multiple-range test, $\alpha=0.01$ and $\mathrm{df}=24$. 
Table 6. Loadings for principal component (PC) analysis of mean genotype color scores (fresh and processed fruit). PCs are linear combinations of the original variables. The loadings are the coefficients (or weights) applied to each variable.

\begin{tabular}{lrr}
\hline \hline Variable & $\mathrm{PCl}$ & $\mathrm{PC} 2$ \\
\hline $\mathrm{L}_{\mathrm{f}}{ }^{*}$ & -0.50 & -0.16 \\
$\mathrm{a}_{\mathrm{f}}{ }^{*}$ & 0.45 & -0.32 \\
$\mathrm{~b}_{\mathrm{f}}{ }^{*}$ & -0.15 & 0.58 \\
$\mathrm{~L}_{\mathrm{p}}^{*}$ & 0.23 & 0.65 \\
$\mathrm{a}_{\mathrm{p}}^{*}$ & 0.49 & -0.22 \\
$\mathrm{~b}_{\mathrm{p}}^{*}$ & 0.48 & 0.24 \\
\hline
\end{tabular}

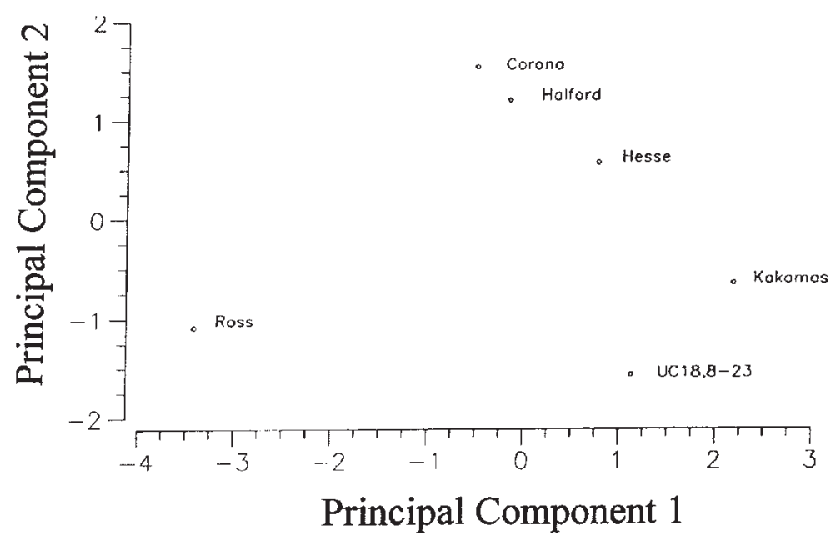

Fig. 1. Bivariate distribution of mean estimates of genotype scores for the first two principal components (PC1 and $\mathrm{PC} 2$ ) of $\mathrm{PC}$ analysis.
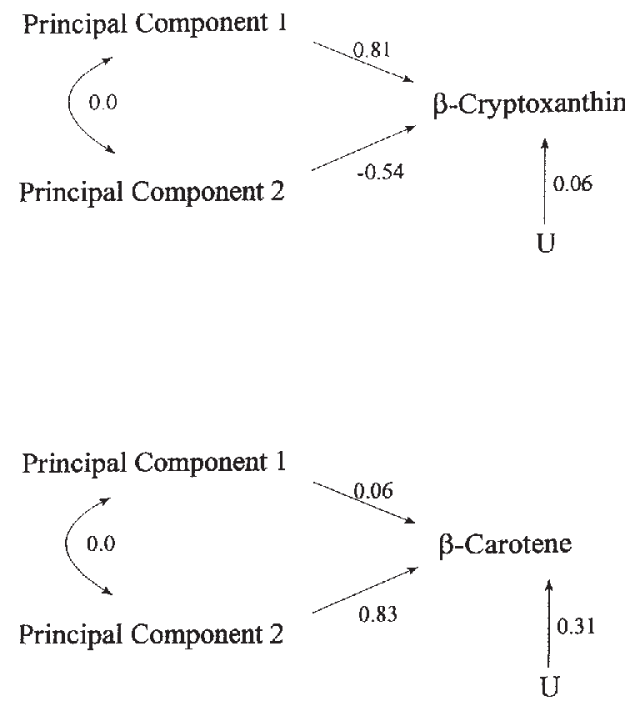

Fig. 2. Path analysis diagrams showing the direct and indirect effects of the principal components on carotenoid concentration $(n=6)$.

Table 7. Pearson product moment correlations and ( $P$ value) between color variables and carotenoid concentration $(n=6)$.

\begin{tabular}{lrc}
\hline \hline Color variable & $\beta$-carotene & $\beta$-cryptoxanthin \\
\hline $\mathrm{L}_{\mathrm{f}}{ }^{*}$ & $-0.39(0.52)$ & $-0.62(0.27)$ \\
$\mathrm{a}_{\mathrm{f}}{ }^{*}$ & $0.04(0.95)$ & $0.98(<0.01)$ \\
$\mathrm{b}_{\mathrm{f}}{ }^{*}$ & $0.81(0.09)$ & $-0.34(0.58)$ \\
$\mathrm{L}_{\mathrm{p}}{ }^{*}$ & $0.54(0.35)$ & $-0.03(0.96)$ \\
$\mathrm{a}_{\mathrm{p}}{ }^{*}$ & $0.05(0.94)$ & $0.93(0.02)$ \\
$\mathrm{b}_{\mathrm{p}}{ }^{*}$ & $0.25(0.68)$ & $0.72(0.18)$ \\
\hline
\end{tabular}

'Ross' has a combined carotenoid concentration that is less than one-fifth that of 'Kakamas'.

$P C$ analysis was used to circumvent CIELAB model-generated correlations among the color variables $\left(L_{\mathrm{f}}{ }^{*}, \mathrm{a}_{\mathrm{f}}{ }^{*}, \mathrm{~b}_{\mathrm{f}}{ }^{*}, \mathrm{~L}_{\mathrm{p}}{ }^{*}, \mathrm{a}_{\mathrm{p}}{ }^{*}\right.$, and $\left.b_{p}{ }^{*}\right)$ and summarize in two dimensions the variability among the six genotypes (Johnson and Wichern, 1992). The first two PCs (PC1 and PC2) accounted for $62 \%$ and $27 \%$ of the standardized variance, respectively. $\mathrm{PC} 1$ had equal loadings on $\mathrm{L}_{\mathrm{f}}{ }^{*}, \mathrm{a}_{\mathrm{f}}{ }^{*}, \mathrm{a}_{\mathrm{p}}{ }^{*}$, and $\mathrm{b}_{\mathrm{p}}{ }^{*}$ and smaller loadings on $\mathrm{b}_{\mathrm{f}}{ }^{*}$ and $\mathrm{L}_{\mathrm{p}} *$ (Table 6). $\mathrm{L}_{\mathrm{f}}{ }^{*}$ and $\mathrm{b}_{\mathrm{f}} *$ had negative loadings; the other variables had positive loadings. Processing reversed the rank order of the genotypes with respect to $\mathrm{L}^{*}$ and $b^{*}$. PC2's loadings were dominated by $\mathrm{L}_{\mathrm{p}}{ }^{*}$ and $\mathrm{b}_{\mathrm{f}}^{*} . \mathrm{PC} 2$ is correlated with variation in $\mathrm{L}^{*}$ that occurs with processing among the genotypes.

A plot of the scores for $\mathrm{PC} 1$ vs. $\mathrm{PC} 2$ revealed three distinct groups for these genotypes (Fig. 1), closely matching the relative concentrations of $\beta$-carotene and $\beta$-cryptoxanthin (Table 5). 'Ross' had negative scores for PC1 and PC2 (group I) . 'UC18,8-23' and 'Kakamas' had negative PC2 scores and positive PC1 scores (group II). 'Corona', 'Halford', and 'Hesse' had positive PC2 scores (group III). 'Hesse' was the only genotype whose grouping based on color data differed from the carotenoid based grouping. This implies that noncarotenoid factors also play a role in peach color variability. In terms of the original color variables, group III genotypes were intermediate in $\mathrm{a}^{*}$ scores, group II genotypes were high in $\mathrm{a}^{*}$ scores, and group I genotypes were low in $\mathrm{a}^{*}$ scores. Groups I and II genotypes were also low in $\mathrm{L}_{\mathrm{p}}{ }^{*}$ scores. Kader et al. (1982), working with a different set of genotypes, found " $a$ " to be the best color variable for discriminating among genotypes and that this variable was highly correlated with carotenoid content.

The linear relationship between the PCs and carotenoid concentration of peach flesh is shown through path analysis (Fig. 2). Variation in the first two PCs described $94 \%$ of the variation in $\beta$ cryptoxanthin concentration among genotypes. However, only $69 \%$ of the variation in $\beta$-carotene concentration was described by these PCs. Perhaps the presence of $\beta$-carotene is partially masked by other pigments (e.g., oxidation products resulting from heat processing).

Both PCs described a direct effect on $\beta$-cryptoxanthin concentration, although PClwas the stronger direct effect. The only important direct effect describing variation in $\beta$-carotene concentration was $\mathrm{PC} 2$. The relationship between carotenoid concentration and PC score was explained by the PC loadings and linear correlations between the CIELAB variables and carotenoid concentrations. PC2 is loaded most heavily on $b_{\mathrm{f}}{ }^{*}$ and $\mathrm{L}_{\mathrm{p}}{ }^{*}$. PCl has diminished loadings for these variables (Table 6). $\beta$-Carotene is most strongly correlated with $b_{f}{ }^{*}$ and $L_{p}{ }^{*}$ and least strongly correlated with $a_{\mathrm{f}}^{*}$ and $\mathrm{a}_{\mathrm{p}}{ }^{*} ; \beta$-cryptoxanthin had the oposite relationship with these variables (Table 7).

The strong correlation between $\mathrm{a}^{*}$ and $\beta$-cryptoxanthin concentration (Table 7) partly explains its utility as a convenient measure of peach maturity and quality. However, the low correlation between color variables and $\beta$-carotene concentration in fresh and processed fruit argue for a more accurate understanding of the role of individual carotenoid pigments in the color and nutritive (provitamin A) value of processed fruit. Spectrophotometric colorimetry of peach flesh color suggests that it may be feasible to define an optimal processed flesh color based on CIELAB color notation and that the statistical methods used here could facilitate pigment analysis. 


\section{Literature Cited}

Curl, A.L. 1959. Carotenoids of cling peaches. Food Res. 24:413-422.

Delwiche, M.J. and R.A. Baumgardner. 1985. Ground color as a peach maturity index. J. Amer. Soc. Hort. Sci. 110:53-57.

Edward E. Judge and Sons, Inc. 1996. The almanac of the canning, freezing preserving Industries. Edward E. Judge And Sons, Inc. Westminister, Md.

Francis, F.J. 1995. Quality as influenced by color. Food Qual. Preference 6:149-155.

Fuleki, T. and F.I. Cook. 1976. Relationship of maturity as indicated by flesh color to quality of canned clingstone peaches. Can. Inst. Food Sci. Technol. J. 9(1):43-46.

Gradziel, T.M. 1994. Changes in susceptibility to brown rot with ripening in three clingstone peach genotypes. J. Amer. Soc. Hort. Sci. 119:101105.

Gradziel, T.M. and D. Wang. 1993. Evaluation of brown rot resistance and its relation to enzymatic browning in clingstone peach germplasm. J. Amer. Soc. Hort. Sci. 1 18:675-679.

Hochberg, Y. 1974. Some conservative generalizations of the T-method in simultaneous inference. J. Multivariate Anal. 4:224-234.

Hunt, R.W.G. 1987. Measuring color. Ellis Horwood. Chichester, U.K. Johnson, R.A. and D.W. Wichern. 1992. Applied multivariate statistical analysis. 3rd ed. Prentice Hall, Upper Saddle River, N.J.

Kader, A.A., C.M. Heintz, and A. Chordas. 1982. Postharvest quality of fresh and canned clingstone peaches as influenced by genotypes and maturity at harvest. J. Amer. Soc. Hort. Sci. 107:947-951.

Khachik, F., G.R. Beecher, and W.R. Lusby. 1989. Separation, identification, and quantification of the major carotenoids in extracts of apricots, pcaches, cantaloupe, and pink grapefruit by liquid chromatography. J. Agr. Food Chem. 37:1465-1473.
Lauber, J.J., G.A. Taylor, and W.O. Drinkwater. 1967. The use of tristimulus colorimetry for the estimation of carotenoid content of raw sweet potato roots. Proc. Amer. Soc. Hort. Sci. 80:497-506.

Lee, C. Y., V. Kagan, A.W. Jaworski, and S.K. Brown. 1990. Enzymatic browning in relation to phenolic compounds and polyphenoloxidase activity among various peach cultivars. J. Agr. Food. Chem. 38:99-101.

Leonard, S.J., B.S. Luh, C.O. Chichester, and M. Simone. 1961. Relationship of fresh clingstone peach color to color and grade after canning. Food Technol. 15:492-494.

MacKinney, G. 1937. Carotenoids of the peach. Plant Physiol. 12:216.

Mitchell, J.H. 1948. The effect of canning and freezing on the carotenoids and ascorbic acid content of peaches. Bul. S.C. Agr. Expt. Sta. No. 372.

U.S. Department of Agriculture National Agricultural Statistics Service. 1996. Agricultural statistics 1995-96. U.S. Govt. Printing Office, Washington, D.C.

Robbins, J.A. and P.P. Moore. 1990. Color change in fresh red raspberry fruit stored at $0,4.5$, or 20C. HortScience 25:1623-1624.

Robertson, J.A., F.I. Meredith, and W.R. Forbus. 1991. Changes in quality characteristics during peach (cv. 'Majestic') maturation. J. Food Qual. 14:197-207.

Shaw, D.V. 1991. Genetic variation for objective and subjective measures of fresh fruit color in strawberries. J. Amer. Soc. Hort. Sci. 1 16:894-898.

Singha, S., T.A. Baugher, E.C. Townsend, and M.C. D'Souza 1991. Anthocyanin distribution in 'Delicious' apples and the relationship between anthocyanin concentration and chromaticity values. J. Amer. Soc. Hort. Sci. 116:497-499.

Voss, D.H. 1992. Relating colorimeter measurement of plant color to the Royal Horticultural Society color charts. HortScience 27:1256-1260.

Williams, W.A., M.B. Jones, and M.W. Demment. 1990. A concise table for path analysis statistics. Agron. J, 82:1022-1024. 